\title{
Dry powdered aerosols of diatrizoic acid nanoparticle agglomerates as a lung contrast agent
}

\author{
Nashwa El-Gendy ${ }^{1}$, Kristin L. Aillon ${ }^{1}$, and Cory Berkland ${ }^{1,2,{ }^{*}}$ \\ ${ }^{1}$ Department of Pharmaceutical Chemistry, The University of Kansas, Lawrence, KS 66047 \\ ${ }^{2}$ Department of Chemical and Petroleum Engineering, The University of Kansas, Lawrence, KS \\ 66047
}

\begin{abstract}
Aerosolized contrast agents may improve the resolution of biomedical imaging modalities and enable more accurate diagnosis of lung diseases. Many iodinated compounds, such as diatrizoic acid, have been shown to be safe and useful for radiographic examination of the airways.

Formulations of such compounds must be improved in order to allow imaging of the smallest airways. Here, diatrizoic acid nanoparticle agglomerates were created by assembling nanoparticles into inhalable microparticles that may augment deposition in the lung periphery. Nanoparticle agglomerates were fully characterized and safety was determined in vivo. After dry powder insufflation to rats, no acute alveolar tissue damage was observed $2 \mathrm{~h}$ post dose. Diatrizoic acid nanoparticle agglomerates possess the characteristics of an efficient and safe inhalable lung contrast agent.
\end{abstract}

\section{Keywords}

diatrizoic acid; contrast medium; pulmonary delivery; dry powder; aerosols; CT imaging

\section{Introduction}

Radiocontrast agents are medical contrast media aimed at improving the visibility of internal body structures for imaging techniques such as magnetic resonance imaging, computed tomography (CT) or radiography (X-ray imaging) (Barrs, 2006; Sanz and Fayad, 2008). There are two basic types of X-ray contrast agents currently approved for human use; barium sulfate and iodinated derivatives of benzene (Barrs, 2006). Barium sulfate suspensions are used strictly for gastrointestinal (GI) tract imaging (Shook and Felson, 1970; Tanomkiat and Galassi, 2000; Walsham and Larsen, 2008). Several iodinated contrast agents have been safely used for many years without serious side effects. These compounds increase the visibility of treated tissues and various iodinated molecules are used clinically today (Ernst et al., 1998; Mukundan et al., 2006; Wisner et al., 1994).

\footnotetext{
C 2010 Elsevier B.V. All rights reserved.

*To whom correspondence should be addressed. The University of Kansas, 2030 Becker Drive, Lawrence, KS 66047. Phone: (785) 864-1455. Fax: (785) 864- 1454. berkland@ku.edu.

Publisher's Disclaimer: This is a PDF file of an unedited manuscript that has been accepted for publication. As a service to our customers we are providing this early version of the manuscript. The manuscript will undergo copyediting, typesetting, and review of the resulting proof before it is published in its final citable form. Please note that during the production process errors may be discovered which could affect the content, and all legal disclaimers that apply to the journal pertain.
} 
Contrast agents for CT examinations are administered by i.v. injection, oral dosing, or rectal administration. Inhalation of contrast agents represents a relatively uncommon procedure. Over the years, many efforts have been made to deliver contrast material to the lungs by inhalation rather than by injection, but results have often been disappointing (Shook and Felson, 1970). In addition, roentogenographic examination of the airways using the conventional liquid contrast media has several disadvantages including poor aerosolization efficiency and potential short residence times (Díaz-López et al., 2010; Fischer and Blaug, 1969; Nadel et al., 1968). More promising results have been obtained by inhalation of powdered contrast media (mostly tantalum) (Nadel et al., 1968; Nadel et al., 1970; Scott and Steiner, 1975); however, these formulations were not pursued because of the difficulty in administration (Lafitte et al., 1982; Strecker et al., 1979), high cost, and lack of approval by the FDA (Flower and Armstrong, 1986; Gamsu and Nadel, 1972).

A major problem with pulmonary delivery of aerosols is poor deposition efficiency as, in some cases; < $10 \%$ of the inhaled drug powder reaches the alveoli (Bhavna et al., 2009; Chan and Chew, 2003; Labiris and Dolovich, 2003; Telko and Hickey, 2005; Young et al., 2007). To address this problem, a controlled nanoparticle agglomeration process has been developed where particles exhibiting an aerodynamic diameter from 1 to $5 \mu \mathrm{m}$ are created to bypass the mouth and throat, resulting in augmented deposition in the lung periphery (Bailey et al., 2008; El-Gendy et al., 2009; Plumley et al., 2009; Schoubben et al., 2010; Tsapis et al., 2002). These porous agglomerates consist of closely-packed nanoparticles that may be easily disseminated throughout the lung (El-Gendy and Berkland, 2009; Raffin et al., 2009; Shi et al., 2007; Tsapis et al., 2002).

Diatrizoic acid, also known as amidotrizoic acid or 3,5-diacetamido-2,4,6-triiodobenzoic acid, is an iodinated radiocontrast agent (Szmigielski et al., 1991a). Many investigations have demonstrated safe and effective contrast enhancement when administrating powdered diatrizoic acid by insufflation and inhalation methods for radiographic imaging of the airways (Mcintire et al., 1998; Szmigielski et al., 1991b; Szmigielski et al., 1991a). Here, diatrizoic acid nanoparticle agglomerates were formulated and characterized. Dissolution studies were also performed for selected nanoparticles and nanoparticle agglomerates. Finally, histological examination of rat lung tissue after dry powder insufflation was performed to determine acute tissue damage.

\section{Materials and methods}

\subsection{Materials}

Diatrizoic acid anhydrous (Dia) and L-leucine (Leu) were purchased from Sigma Chemical Co., St Louis, MO, USA. Ethanol, potassium dihydrogen phosphate $\left(\mathrm{KH}_{2} \mathrm{PO}_{4}\right)$, disodium hydrogen phosphate $\left(\mathrm{Na}_{2} \mathrm{HPO}_{4}\right)$ and sodium chloride $(\mathrm{NaCl})$ were purchased through Fisher Scientific, Fair Lawn, NJ, USA. Floatable dialysis membrane units (regenerated cellulose membranes manufactured from natural cellulose reconstituted from cotton linters, Mw cutoff $=10,000 \mathrm{Da}$ ) were obtained from Spectrum Laboratories Inc., Rancho Dominguez, CA, USA. Double-distilled water was used throughout the study, provided by an EASYpure ${ }^{\circledR}$ RODI (Barnstead International, Model \# D13321, Dubuque, Iowa, USA).

\subsection{Preparation and characterization of diatrizoic acid nanosuspensions}

Nanosuspensions were prepared using a precipitation technique. Briefly, solutions of diatrizoic acid in ethanol were prepared at a concentration of $0.2 \% \mathrm{w} / \mathrm{v}$ and directly injected into water at a rate of $1 \mathrm{~mL} / \mathrm{min}$. Various solvent/ non-solvent ratios were used under ultrasonication (probe-type sonicator, Fisher Scientific, Sonic Dismembrator) operating with 
an amplitude of $48 \%$ or under homogenization (probe-type homogenizer, Tissue tearor, Biospec Products, Inc.), as shown in Table 1.

The particle size and polydispersities of the nanoparticle suspensions were determined by dynamic light scattering (Brookhaven, ZetaPALS, Holtsville, NY, USA). The same instrument was used to determine the zeta potential of the nanoparticles in $1 \mathrm{mM}$ potassium chloride solution. Three runs of 15 cycles were acquired, and the mean zeta potential was recorded. Some samples were frozen at $-80^{\circ} \mathrm{C}$ and lyophilized at a temperature of $-50^{\circ} \mathrm{C}$ and under vacuum of 0.03 Mbar using a Labconco bench top lyophilizer (FreeZone 1, Kansas City, MO). Drying lasted for $36 \mathrm{~h}$ to remove all appreciable water content. Lyophilized powder was stored at room temperature for further characterization.

\subsection{Agglomeration of diatrizoic acid nanoparticles}

Nanoparticle colloids were destabilized via ionic interactions to control the agglomeration of nanoparticles. Briefly, diatrizoic acid nanoparticle agglomerates were obtained by addition of a flocculating agent, L-leucine powder. The amount of L-leucine added was adjusted to a drug:leucine ratio equal to 1:1. Directly after addition, the suspensions were subjected to vigorous mixing via homogenization at $25,000 \mathrm{rpm}$ for $30 \mathrm{sec}$. The size of nanoparticle agglomerates that were incubated with flocculating agent for $3 \mathrm{~h}$ was measured in Isoton diluent using a Coulter Multisizer 3 (Beckman Coulter Inc.) equipped with a $100 \mu \mathrm{m}$ aperture. The flocculated suspensions were kept overnight at room temperature to allow evaporation of ethanol and then frozen at $-80^{\circ} \mathrm{C}$ before being lyophilized for further analysis.

\subsection{Characterization of the selected nanoparticle agglomerate}

2.4.1. Particle geometric size and tap density measurements-The geometric size and size distribution of the dispersed nanoparticle agglomerates as well as the resuspended lyophilized powder were measured using a Coulter Multisizer ${ }^{\mathrm{TM}} 3$.

Tap densities were determined for the dried powders and compared with that of the diatrizoic acid powder as received. Fifty $\mathrm{mg}$ of powder was poured into a $10 \mathrm{~mL}$ graduated measuring cylinder. The measuring cylinder was tapped vertically against a padded bench 20 times and the tap volume $\left(\mathrm{V}_{\mathrm{t}}\right)$ was recorded. The process was repeated at least three times and the average was taken. Tap densities $\left(\rho_{\text {tap }}\right)$ of powders were calculated by dividing the mass by the tapped volume recorded (Kumar et al., 2001; Staniforth, 2002).

\subsubsection{Measurement of mass-median aerodynamic diameter}

The theoretical mass-mean aerodynamic diameter $\left(\mathrm{d}_{\mathrm{aero}}\right)$ of the nanoparticle agglomerates was determined from the geometric particle size and tap density using the following relationship (Chow et al., 2007; Vanbever et al., 1999b):

$$
\mathbf{d}_{\mathrm{aero}}=\mathrm{d}_{\mathrm{geo}}\left\lceil\frac{\left(\rho / \rho_{\text {ref }}\right)^{0.5}}{\gamma}\right\rceil
$$

where $d_{g e o}=$ geometric diameter, $\gamma=$ shape factor (for a spherical particle, $\gamma=1$, the particles in this study were assumed to be spherical), $\rho=$ particle bulk density and $\rho_{\text {ref }}=$ water mass density $\left(1 \mathrm{~g} / \mathrm{cm}^{3}\right)$. Tap density measurements underestimate particle bulk densities since the volume of particles measured includes the interstitial space between the particles. The true particle density, and the aerodynamic diameter of a given powder, may be expected to be slightly larger than reported (Fiegel et al., 2008). 
The aerodynamic size distributions of the agglomerate powders were measured directly from lyophilized powders by time-of-flight measurement using an Aerosizer LD (Amherst Instruments, Hadely, MA, USA) equipped with a $700 \mu \mathrm{m}$ aperture operating at 6 psi. For this step, $\sim 5 \mathrm{mg}$ of the powder were added to the Aerosizer and data were collected over $\sim 60$ sec under high shear force $(\sim 3.4 \mathrm{kPa})$.

\subsubsection{In vitro aerosolization of nanoparticle agglomerates}

Aerodynamic characteristics of selected nanoparticle agglomerates were studied using a Tisch Ambient Cascade Impactor (Tisch Environmental, Inc., Village of Cleves, OH, USA). The study was carried out by applying $\sim 10 \mathrm{mg}$ powder manually into the orifice of the instrument at an air flow rate of $\sim 30 \mathrm{~L} / \mathrm{min}$. Furthermore, the dry powders were resuspended in water $(1 \mathrm{mg} / \mathrm{mL}$ ) and applied into the instrument through a nebulizer (PARI LC Star® Reusable Nebulizer connected to compressor nebulizer system; PRONEB® Ultra II, PARI Respiratory Equipment, Inc., Midlothian, VA, USA) for $\sim 30 \mathrm{~min}$ at the same flow rate. Cutoff particle aerodynamic diameters for each stage of the impactor were: pre-separator (10.00 $\mu \mathrm{m})$, stage $0(9.00 \mu \mathrm{m})$, stage $1(5.8 \mu \mathrm{m})$, stage $2(4.7 \mu \mathrm{m})$, stage $3(3.3 \mu \mathrm{m})$, stage $4(2.1$ $\mu \mathrm{m})$, stage $5(1.1 \mu \mathrm{m})$, stage $6(0.7 \mu \mathrm{m})$, stage $7(0.4 \mu \mathrm{m})$ and filter $(0 \mu \mathrm{m})$. Nanoparticle agglomerates deposited on each stage of the impactor were determined by measuring the difference in weight of filters placed on the stages. The percent emitted fraction (\%EF) and fine particle fractions of the total dose $\left(\mathrm{FPF}_{\mathrm{TD}}\right.$ ) were then calculated (Lechuga-Ballesteros et al., 2008; Yang et al., 2008). The percent emitted fraction was determined from the following equation:

$\%$ Emitted fraction $(\% \mathrm{EF})=\frac{\text { Total particle mass collected from the stages of the impactor }}{\text { Total particle mass entered into the impactor }} \times 100$

The fine particle fraction of the total dose $\left(\mathrm{FPF}_{\mathrm{TD}}\right)$ was calculated as the percentage of aerosolized particles that reached the lower seven stages of the impactor (corresponding to aerodynamic diameters below $5.8 \mu \mathrm{m}$ ), or the lower five stages (corresponding to aerodynamic diameters below $3.3 \mu \mathrm{m}$ ) according to the following equation:

$\%$ Fine particle fraction $\left(\mathrm{FPF}_{\mathrm{TD}}\right)=\frac{\text { Powder mass recovered from terminal stages of the impactor }}{\text { Total particle mass recovered in the impactor }} \times 100$

In addition, the mass median aerodynamic diameter, MMAD, and geometric standard deviation, GSD, were obtained by a linear fit of the cumulative percent less-than the particle size range by weight plotted on a probability scale as a function of the logarithm of the effective cut-off diameter (Pham and Wiedmann, 2001; Vanbever et al., 1999a).

\subsection{Particle imaging}

Nanoparticles and nanoparticle agglomerates were imaged via JEOL 1200 EXII Transmission electron microscope to evaluate their size and morphology. Initially, carboncoated grids (Electron Microscopy Sciences) were floated on a droplet of the suspensions on a glass microscope slide to permit the adsorption of the particles onto the grid. After this, the grid was blotted with a filter paper and air dried for $1 \mathrm{~h}$.

\subsection{Thermal analysis}

Differential scanning calorimetry (DSC) curves of diatrizoic powder as received, nanoparticles and nanoparticle agglomerates were collected on a Q100 DSC from TA Instruments using aluminum hermetic pans containing $2-5 \mathrm{mg}$ of sample. Unless indicated, 
all DSC curves were collected from 25 to $400^{\circ} \mathrm{C}$ with a heating rate of $20^{\circ} \mathrm{C} / \mathrm{min}$ under dry nitrogen at $50 \mathrm{~mL} / \mathrm{min}$. The effect of heating rate on the peak transition was then observed using DSC by heating the material at different heating rates $\left(5,10\right.$, and $20^{\circ} \mathrm{C} / \mathrm{min}$.). Thermogravimetric analysis (TGA) was performed using a Q50 TGA from TA Instruments. A platinum sample pan was loaded with $\sim 5 \mathrm{mg}$ of sample and heated from 25 to $400^{\circ} \mathrm{C}$ at a rate of $10^{\circ} \mathrm{C} / \mathrm{min}$ under dry nitrogen flow rate of $40 \mathrm{~mL} / \mathrm{min}$. Data analysis was completed using Universal Analysis 2000 (Version 4.3A) software that was provided by TA Instruments.

\subsection{Process yield and loading efficiency measurements}

After lyophilization, particle yield was determined using the following equation.

$$
\% \text { Process yield }=\frac{\text { Recovered mass }}{\text { Mass entered into the experiment }} \times 100
$$

Diatrizoic acid loading efficiency in the dry powders was determined by dispersing $1 \mathrm{mg}$ of the lyophilized powder in $10 \mathrm{~mL}$ ethanol. The obtained suspension was sonicated in a bathtype sonicator for $30 \mathrm{~min}$ and centrifuged at $~ 15,000 \mathrm{rpm}$ for $30 \mathrm{~min}$ to remove insoluble ingredients. Then, the amount of diatrizoic acid in the supernatant was determined spectrophotometrically (Agilent C) at $238 \mathrm{~nm}$. Drug loading was defined as follows:

$$
\% \text { Loading }=\frac{\text { Recovered diatrizoic acid mass }}{\text { Total mass }} \times 100
$$

\subsection{Dissolution studies}

The in vitro dissolution of diatrizoic acid from the prepared nanoparticles and nanoparticle agglomerates was determined under sink conditions and compared with the dissolution characteristics of the drug powder as received. An accurately weighed amount of the lyophilized powder equivalent to $1 \mathrm{mg}$ diatrizoic acid was dispersed in $10 \mathrm{~mL}$ phosphate buffered saline (PBS, pH 7.4) and was suspended into a floatable dialysis membrane unit (Mw cut-off $=10,000 \mathrm{Da}$ ). The unit was allowed to float in a beaker containing $350 \mathrm{~mL}$ PBS and the whole assembly was stirred at a constant speed $(100 \mathrm{rpm})$ using a magnetic stirrer (Barnstead, Thermolyne MIRAK ${ }^{\mathrm{TM}}$ ) at $37 \pm 0.5^{\circ} \mathrm{C}$. Aliquots were withdrawn from the dialysis bag and replaced with fresh medium at predetermined time intervals for a total period of $8 \mathrm{~h}$. Then, the drug content was measured using a reserved phase HPLC method as described below. Studies were conducted in triplicate.

\subsection{HPLC analysis of diatrizoic acid}

Quantification of diatrizoic acid dissolution samples were analyzed using a reverse-phase HPLC. The HPLC system consisted of a solvent delivery pump (Shimadzu LC-10AT), a controller (Shimadzu SCL-10A), an autoinjector (Shimadzu SIL-10AxL), and a UV detector (Shimadzu SPD-10A). The peak areas were integrated using Shimadzu Class VP (Version 4.3). The drug was separated on Phenomenex Synergi Hydro-RP C18 column $(250 \times 2 \mathrm{~mm}$, $4 \mu \mathrm{m}$ particle size). Standards and samples were prepared in MillQ water. Mobile phase consisted of a mixture of methanol and $10 \mathrm{mM}$ phosphate buffer $(5: 95 \mathrm{v} / \mathrm{v})$, adjusted to $\mathrm{pH}$ 3.5 with phosphoric acid. Diatrizoic acid was eluted isocratically at a mobile phase flow rate of $0.3 \mathrm{~mL} / \mathrm{min}$ and monitored with a UV detector operating at $225 \mathrm{~nm}$. The run time for the assay was $10 \mathrm{~min}$, and the retention time for the drug was 7.1 $\pm 0.2 \mathrm{~min}$ (Farag and Wells, 1997; Seitz et al., 2006). 


\subsection{Animal Insufflation}

Female Sprague-Dawley rats (200-250 grams; Charles River Laboratories Inc., Wilmington, MA, USA) were housed in temperature and humidity controlled rooms with free access to food and water and maintained on a $12 \mathrm{~h}$ light/dark cycle. Rats were anesthetized by a 67.5 $\mathrm{mg} / \mathrm{kg}$ ketamine, $3.5 \mathrm{mg} / \mathrm{kg}$ xylazine and $0.66 \mathrm{mg} / \mathrm{kg}$ acepromazine subcutaneous cocktail. While under anesthesia, rats were placed on a heating pad to maintain a body temperature of $37^{\circ} \mathrm{C}$. Diatrizoic acid nanoparticle agglomerates $(10 \mathrm{mg})$ was administered by intratracheal insufflation using a PennCentury DP-4 dry powder insufflator (Penn-Century Inc, Philadelphia, PA, USA) using $3 \mathrm{~mL}$ of air. At the end of the experiment, the rats were euthanized by isoflurane inhalation overdose followed by harvest of major organs. All animal procedures were conducted according to guidelines approved by The University of Kansas Institutional Animal Care and Use Committee.

\subsection{Histology of Lung Tissue}

Two hours post insufflation, rats were euthanized as described above and the lungs were removed and stored in $10 \%$ neutral buffered formalin. Tissue samples were taken to the pathology lab at Lawrence Memorial Hospital (Lawrence, KS, USA). At the lab, tissues were embedded in paraffin wax and slices from the tissues were stained with hematoxylin and eosin $(\mathrm{H}$ and $\mathrm{E})$ dyes. The results of the tissues slides were discussed with a pathologist.

\section{Results and discussion}

\subsection{Fabrication of diatrizoic acid nanoparticles}

Various methods have been reported for generating nanoparticles of poorly water soluble compounds. A precipitation method was selected to produce diatrizoic acid nanoparticles (Bilati et al., 2005; Govender et al., 1999; Matteucci et al., 2006). Using this technique, nanoparticle suspensions were designed with different ratios of ethanol and water as a means to achieve a small particle size. Formulations prepared using 5/15, 5/25 and 2/28 solvent/ non-solvent ratios produced large particle sizes (up to $900 \mathrm{~nm}$ ) when sonication or homogenization was used during precipitation (Table 1).

Attempts to create diatrizoic acid nanoparticles using 1/29 ratio yielded reasonable particle sizes $(\sim 145-188 \mathrm{~nm})$ but offered very low nanoparticle yields. The most successful solvent/ non-solvent ratio and process for generating diatrizoic acid nanosuspensions was 2.5/25 using sonication (D9 on Table I). This formula demonstrated small particle size and was selected for dry powder formulations. Only a slight change in zeta potential was observed with different ratios of the solvents and the values ranged from 22-26 mV (Table 1).

\subsection{Agglomerated diatrizoic acid nanoparticles yielded desirable aerosol characteristics}

The mechanism to control nanoparticle agglomeration is mainly driven by leveraging the competitive processes of attraction (van der Waals force) and repulsion (electrostatic repulsive force, steric hindrance or both) (Kumar and Jain, 2007; Shi and Berkland, 2006). The amino acid, L-leucine, was used as a flocculating agent in these studies. Leucine destabilizes the diatrizoic acid colloid by masking the nanoparticle charge (Shur et al., 2008; Young et al., 2002). Agglomeration produced $~ 2.4 \mu \mathrm{m}$ particles consisting of closely-packed diatrizoic acid nanoparticles. The average particle size of resuspended lyophilized powders increased to some extent when compared to the nanoparticle agglomerates in suspension prior to lyophilization (Table 2 and Fig. 1). This may be due to the deposition of nanoparticles on agglomerates during lyophilization or to cohesion between agglomerates as a result of drying (Shi et al., 2007). 
Tap density of the nanoparticle agglomerate powder was determined to be $0.05 \pm 0.01 \mathrm{~g} /$ $\mathrm{cm}^{3}$. This value was used for further calculations (Table 2). The main physical parameter that predicts the site of aerosol deposition within the lungs is the aerodynamic diameter $\left(\mathrm{d}_{\text {aero }}\right)$. The theoretical mass-mean aerodynamic diameter $\left(\mathrm{d}_{\mathrm{aero}}\right)$ of the nanoparticle agglomerate formulation as determined from the geometric particle size and tap density was $\sim 1 \mu \mathrm{m}$ (Table 2). Diatrizoic acid nanoparticle agglomerates with $\mathrm{d}_{\text {aero }}$ in this range may be expected to reach the alveolar region of the lungs (Fiegel et al., 2004). The aerodynamic diameter of the flocculated nanoparticles, measured by an Aerosizer LD, was $\sim 1.2 \mu \mathrm{m}$ (Table 2 and Fig. 2). It was also clear that the aerodynamic size distribution was narrower than the geometric size distribution (Fig. 1). When compared to the geometric diameter, the lower aerodynamic diameter implied a low density for nanoparticle agglomerates.

Cascade impaction studies were carried out for both dry powder and resuspended dry powder at an air flow rate of $\sim 30 \mathrm{~L} / \mathrm{min}$ (Fig. 3) and compared with that for drug as received. Most nanoparticle agglomerates were deposited in stages 5-7 of the cascade impactor which was indicative of efficient aerosolization and a high fine particle fraction. On the other hand, the drug as received deposited mainly in the first stages whether it was tested as dry powder or nebulized as resuspended powder. The aerosolization efficacy was represented by the percent emitted fraction (\%EF), fine particle fraction of the total dose $\left(\mathrm{FPF}_{\mathrm{TD}}\right)$, mass-median aerodynamic diameter (MMAD) and geometric standard deviation (GSD). The high emitted fraction of nanoparticle agglomerates obtained at the tested flow rate $(\sim 76-88 \%)$ suggested efficient aerosolization of the powder. However, using the nebulizer for delivering the resuspended dry powder achieved slightly higher percent emitted fraction (Table 3). Cascade impaction data demonstrated that the anticipated total lung deposition (i.e. $\mathrm{FPF}_{\mathrm{TD}}<5.8 \mu \mathrm{m}$ ) was about $93-96 \%$ and deep lung deposition (i.e. $\mathrm{FPF}_{\mathrm{TD}}<3.3 \mu \mathrm{m}$ ) was $\sim 80 \%$ for diatrizoic acid dry powder and resuspended formulation D9 delivered using a nebulizer. The formulated nanoparticle agglomerates had small massmedian aerodynamic diameters (i.e. $<3 \mu \mathrm{m}$ ), which would make them suitable for deep lung deposition. From the cascade impaction results (Table 3), the MMAD of D9 nanoparticle agglomerates was determined to be $\sim 1.5 \mu \mathrm{m}$. This experimental MMAD matched well with the theoretical MMAD calculated from the tapped density $(1.0 \mu \mathrm{m})$. The geometric standard deviation (GSD) was determined using the equation:

$$
\operatorname{GSD}=\left(\frac{\mathrm{d}_{84.13 \%}}{\mathrm{~d}_{15.87 \%}}\right)^{1 / 2}
$$

where $d_{n}$ is the diameter at 15.87 and $84.13 \%$ for the cumulative distribution. The massmean geometric size of the D9 agglomerates was $2.8 \mu \mathrm{m}$ with a GSD of $\sim 2.2$ (Table 3).

\subsection{Transmission Electron Microscopy}

The investigated D9 nanoparticles exhibited a round shape and a diameter less than $200 \mathrm{~nm}$ (Fig. 4A). TEM images of D9 nanoparticle agglomerates showed that the nanoparticles were flocculated into micron sized agglomerates of approximately $2 \mu \mathrm{m}$ resembling a collection of round diatrizoic acid nanoparticles (Fig. 4B).

\subsection{Thermal analysis}

The DSC data of diatrizoic acid as received exhibited a broad endothermic event at $164.8^{\circ} \mathrm{C}$ followed by an exothermic peak at $229.6^{\circ} \mathrm{C}$ and then another endothermic peak at $334.2^{\circ} \mathrm{C}$ followed by subsequent degradation of the compound (Fig. 5). The early endothermic peak may be suggestive of the dihydrate form of the compound and the second small observed melting exotherm may be indicative of the dehydrated form of the molecule. The melting 
endotherm at $334.2^{\circ} \mathrm{C}$ may be evidence of the characteristic endothermic peak of the anhydrous form of diatrizoic acid. In a similar experiment, the material was also heated from 25 to $270^{\circ} \mathrm{C}$ (the temperature prior to the characteristic peak of the drug) with a heating rate of $20^{\circ} \mathrm{C} / \mathrm{min}$ under dry nitrogen at $50 \mathrm{~mL} / \mathrm{min}$ followed by cooling the powder to room temperature using aluminum hermetic pans with holes. Then, the material was re-heated to $400^{\circ} \mathrm{C}$ at the same rate. This experiment demonstrated the disappearance of the first endothermic and exothermic peaks and only the appearance of the sharp melting endotherm at $334.2^{\circ} \mathrm{C}$ was observed (see supplementary Figure 1). These data support the hypothesis of water loss from the hydrated compound. The effect of heating rate on these transitions was then investigated using DSC by heating the material at different heating rates $(5,10$, and $20^{\circ} \mathrm{C} / \mathrm{min}$.). These experiments (data not shown) revealed that the onset temperature of these peaks did not significantly change. Also, TGA was performed on the material and a small step change in TGA was started at $95.9^{\circ} \mathrm{C}$ leading to $4.2 \%$ loss at $114^{\circ} \mathrm{C}$, which may possibly be due to the loss of water from the compound. A large weight loss began at $308.5^{\circ} \mathrm{C}$ ended with a $55.7 \%$ loss at $335^{\circ} \mathrm{C}$ which could be attributed to the characteristic endotherm of diatrizoic acid (Fig. 6).

The nanoparticles showed a very small and broad endotherm that began at $78.8^{\circ} \mathrm{C}$ suggesting the presence of a small amount of residual water compared to the drug as received (Fig. 5). The earlier appearance and the very small sharpness of the characteristic melting endotherm $\left(300^{\circ} \mathrm{C}\right)$ of the drug may be due to the small particle size (i.e. high surface area) of the nanoparticles or, perhaps, to the presence of some surface defects or amorphous material. This small peak immediately started to degrade. In addition, the curve exhibited a small melting endotherm at $\sim 300^{\circ} \mathrm{C}$. A very low amount of residual solvent was observed from the nanoparticles near $90^{\circ} \mathrm{C}$ by TGA (Fig. 6). Nanoparticles exhibited only $17.29 \%$ weight loss over the temperature range starting at $\sim 320^{\circ} \mathrm{C}$.

Diatrizoic acid in the nanoparticle agglomerates demonstrated a small and broad melting endotherm at $79.8^{\circ} \mathrm{C}$, which was slightly larger than the nanoparticles. This result also suggested retention of a very small amount of solvent within agglomerates. Furthermore, a very large endotherm began at $274.4^{\circ} \mathrm{C}$, followed by subsequent degradation of the drug. The shift of the characteristic melting endotherm of the drug in the nanoparticles agglomerates may be due to large surface area that is retained in these particles. It may also be attributed to the overlap of this peak with the sharp melting endotherm of ${ }_{\mathrm{L}}$-leucine that usually appears at $323.7^{\circ} \mathrm{C}$. No significant mass loss was observed from the nanoparticle agglomerates near $70^{\circ} \mathrm{C}$ by TGA (Fig. 6), reiterating that the lyophilization process removed nearly all of the water. On the contrary, nanoparticle agglomerates showed a gradual decrease in weight over this temperature range with a weight loss of $53 \%$ near $180^{\circ} \mathrm{C}$ followed by a very high weight loss approaching $97.3 \%$ at $280^{\circ} \mathrm{C}$. This may support the hypothesis of degradation of the drug at higher temperature (Fig. 6).

\subsection{Dry powder yield and loading efficiency of diatrizoic acid}

The yield of the mass recovered for processed nanoparticle agglomerates was determined (Table 2). The yield of nanoparticles agglomerates recovered as dry powders were considerably high $(\sim 86 \%)$ which indicated efficient processing with minimum batch variability. The loading efficiency of diatrizoic acid in the prepared nanoparticle agglomerates D9 was found to be $\sim 85 \%$ (Table 2), thus representing a negligible loss of drug during preparation.

\subsection{Dissolution studies of diatrizoic acid from the nanoparticles agglomerates}

A dissolution study of diatrizoic acid was carried out for the prepared nanoparticles and nanoparticle agglomerates and compared to the drug as received. The cumulative percentage 
of drug dissolved from nanoparticle agglomerates reached $100 \%$ after $2 \mathrm{~h}$, which was slower than that of nanoparticles which exhibited 100\% after $90 \mathrm{~min}$. On the other hand, the dissolution behavior of diatrizoic acid from the nanoparticle agglomerates was faster than that of the drug as received which required $4 \mathrm{~h}$ to dissolve completely. This finding was the expected result of increasing the surface area by decreasing the particle size. Linear regression analysis for the release data was done to determine the order of release. Zeroorder, first-order and Higuchi diffusion equations were applied to all dissolution results. Linear regression analysis of the dissolution data concluded that the drug was released by the Higuchi mechanism in all cases, as expected (Table 4). A two-way Analysis of Variance (ANOVA) was performed to determine the significance of differences in diatrizoic acid dissolution kinetics. Significant differences existed between nanoparticles, nanoparticle agglomerates and diatrizoic acid powder as received. This suggested an improvement $(\mathrm{P}<0.05)$ in the dissolution behavior of the nanoparticles and nanoparticle agglomerates when these were individually compared to the diatrizoic acid powder as received.

\subsection{Lung Tissue Histology}

Histological examination of the lung tissue of rats that were insufflated with nanoparticle agglomerates $(10 \mathrm{mg})$ was compared to normal rat lung tissue to assess acute tissue toxicity of the nanoparticle agglomerates. Since the insufflation technique may cause heterogeneous drug distribution, both the left and right lungs were examined separately. No alveolar tissue damage or inflammation was present throughout both the right and left lungs (Fig. 8). These findings were in agreement with other studies showing diatrizoic acid safety after inhalation (Szmigielski et al., 1991b;Szmigielski et al., 1991a). The results also indicated that there was no acute toxicity associated with $\mathrm{L}-\mathrm{leucine}$, the flocculating agent.

\section{Conclusion}

Aerosolized radiocontrast agents may yield several advantages over conventional injection of contrast media for improving airway examination if significant quantities can be safely and effectively disseminated to the pulmonary bed. Diatrizoic acid is known to provide substantial radiopacity and it is the root compound for many intravenous contrast agents on the market today. Here, diatrizoic acid nanoparticle suspensions were successfully prepared yielding $~ 136 \mathrm{~nm}$ nanoparticles without employing excipients. Nanoparticle suspensions were agglomerated using L-leucine and dried to yield powders. Nanoparticle agglomerates were efficiently aerosolized and offered a high fine particle fraction suitable for accessing the peripheral lung. Nanoparticle agglomerates also exhibited faster diatrizoic acid dissolution when compared to the stock powder. Histological examination of lung tissue showed no acute toxicity or inflammation after insufflation of dry powder nanoparticle agglomerates. Overall, diatrizoic acid nanoparticle agglomerates offered a promising radiocontrast agent for safe and effective lung visualization.

\section{Supplementary Material}

Refer to Web version on PubMed Central for supplementary material.

\section{Acknowledgments}

We would like to acknowledge support for this work from the Coulter Foundation, the Higuchi Biosciences Center, and the Cystic Fibrosis Foundation as well as additional lab funding from the American Heart Association, the NIH (R03 AR054035, P20 RR016443 and T32 GM08359-11) and the Department of Defense. In addition, we acknowledge the support of the NSF (CHE 0719464). We also thank Prof. C. Russ Middaugh for the use of laboratory equipment, the KU Microscopy Lab for assistance with electron microscopy and Dr. Mike Thompson and staff at the Lawrence Memorial Hospital Pathology Lab for histology slide processing and consultation. 


\section{References}

Bailey MM, et al. Pure insulin nanoparticle agglomerates for pulmonary delivery. Langmuir 2008;24:13614-13620. [PubMed: 18959432]

Barrs TJ. Overview of radiopaque drugs. Am J Health Syst Pharm 2006;63:2248-2255. [PubMed: 17090746]

Bhavna, et al. Techniques to develop and characterize nanosized formulation for salbutamol sulfate. $\mathbf{J}$ Mater Sci Mater Med 2009;20:71-76.

Bilati U, et al. Development of a nanoprecipitation method intended for the entrapment of hydrophilic drugs into nanoparticles. Eur J Pharm Sci 2005;24:67-75. [PubMed: 15626579]

Chan H-K, Chew NYK. Novel alternative methods for the delivery of drugs for the treatment of asthma. Advanced Drug Delivery Reviews 2003;55:793-805. [PubMed: 12842601]

Chow AHL, et al. Particle Engineering for Pulmonary Drug Delivery. Pharmaceutical Research 2007;24:411-437. [PubMed: 17245651]

Díaz-López R, et al. Liquid Perfluorocarbons as Contrast Agents for Ultrasonography and 19F-MRI. Pharmaceutical Research 2010;27:1-16. [PubMed: 19902338]

El-Gendy N, Berkland C. Combination chemotherapeutic dry powder aerosols via controlled nanoparticle agglomeration. Pharm Res 2009;26:1752-1763. [PubMed: 19415471]

El-Gendy N, et al. Budesonide nanoparticle agglomerates as dry powder aerosols with rapid dissolution. J Pharm Sci 2009;98:2731-2746. [PubMed: 19130469]

Ernst S, et al. Comparison of Iohexol and Barium Sulfate as Gastrointestinal Contrast Media in MidSized Psittacine Birds. Journal of Avian Medicine and Surgery 1998;12:16-20.

Farag SA, Wells CE. Capillary Electrophoresis Determination of Diatrizoic Acid and its Impurities in Diatrizoate Radiopaque Solutions. Mikrochim. Acta 1997;126:141-145.

Fiegel J, et al. Poly(ether-anhydride) dry powder aerosols for sustained drug delivery in the lungs. J Control Release 2004;96:411-423. [PubMed: 15120898]

Fiegel J, et al. Preparation and in vivo evaluation of a dry powder for inhalation of capreomycin. Pharm Res 2008;25:805-811. [PubMed: 17657592]

Fischer HW, Blaug SM. Aerosol bronchography. Radiology 1969;92:150-154. [PubMed: 5762071]

Flower, CDR.; Armstrong, P. Bronchography in diagnostic radiology. In: Allison, DJ.; Grainger, RG., editors. Anglo-American textbook of imaging. Edinburgh: Churchill Livingstone; 1986. p. 135

Gamsu G, Nadel JA. New technique for roentgenographic study of airways and lungs using powdered tantalum. Cancer 1972;30:1353-1357. [PubMed: 5083072]

Govender T, et al. PLGA nanoparticles prepared by nanoprecipitation: drug loading and release studies of a water soluble drug. J Control Release 1999;57:171-185. [PubMed: 9971898]

Kumar PV, Jain NK. Suppression of agglomeration of ciprofloxacin-loaded human serum albumin nanoparticles. AAPS PharmSciTech 2007;8:17. [PubMed: 17408217]

Kumar V, et al. Compression, compaction, and disintegration properties of low crystallinity celluloses produced using different agitation rates during their regeneration from phosphoric acid solutions. AAPS PharmSciTech 2001;2:E7. [PubMed: 14727882]

Labiris NR, Dolovich MB. Pulmonary drug delivery. Part I: physiological factors affecting therapeutic effectiveness of aerosolized medications. Br J Clin Pharmacol 2003;56:588-599. [PubMed: 14616418]

Lafitte JJ, et al. Laryngo-tracheo-bronchography by inhalation. Preliminary experience. J Radiol 1982;63:397-402. [PubMed: 7131406]

Lechuga-Ballesteros D, et al. Trileucine improves aerosol performance and stability of spray-dried powders for inhalation. J Pharm Sci 2008;97:287-302. [PubMed: 17823950]

Matteucci ME, et al. Drug nanoparticles by antisolvent precipitation: mixing energy versus surfactant stabilization. Langmuir 2006;22:8951-8959. [PubMed: 17014140]

Mcintire GL, et al. Pulmonary Delivery of Nanoparticles of Insoluble, Iodinated CT X-ray Contrast Agents to Lung Draining Lymph Nodes in Dogs. J Pharm Sci 1998;87:1466-1470. [PubMed: 9811507] 
Mukundan S Jr, et al. A liposomal nanoscale contrast agent for preclinical CT in mice. AJR Am J Roentgenol 2006;186:300-307. [PubMed: 16423931]

Nadel JA, et al. Powdered tantalum as a medium for bronchography in canine and human lungs. Invest Radiol 1968;3:229-238. [PubMed: 5678890]

Nadel JA, et al. Powdered tantalum. N Engl J Med 1970;283:281-286. [PubMed: 5427057]

Pham S, Wiedmann TS. Note: dissolution of aerosol particles of budesonide in Survanta, a model lung surfactant. J Pharm Sci 2001;90:98-104. [PubMed: 11064383]

Plumley C, et al. Nifedipine nanoparticle agglomeration as a dry powder aerosol formulation strategy. Int J Pharm 2009;369:136-143. [PubMed: 19015016]

Raffin PR, et al. Agglomerates Containing Pantoprazole Microparticles: Modulating the Drug Release. AAPS PharmSciTech 2009;10:335-345. [PubMed: 19319687]

Sanz J, Fayad ZA. Imaging of atherosclerotic cardiovascular disease. Nature 2008;451:953-957. [PubMed: 18288186]

Schoubben A, et al. Simple and scalable method for peptide inhalable powder production. Eur J Pharm Sci 2010;39:53-58. [PubMed: 19879945]

Scott KWM, Steiner GM. Postmortem assessment of chronic airways obstruction by tantalum bronchography. Thorax 1975;30:405-414. [PubMed: 1179324]

Seitz W, et al. Novel applications of highly sensitive liquid chromatography/mass spectrometry/mass spectrometry for the direct detection of ultra-trace levels of contaminants in water. Rapid Commun Mass Spectrom 2006;20:2281-2285. [PubMed: 16810705]

Shi L, et al. Biodegradable nanoparticle flocculates for dry powder aerosol formulation. Langmuir 2007;23:10897-10901. [PubMed: 17894513]

Shi LJ, Berkland C. pH-Triggered dispersion of nanoparticle clusters. Advanced Materials 2006;18:2315-2319.

Shook CD, Felson B. Inhalation bronchography. Chest 1970;58:333-337. [PubMed: 5506625]

Shur J, et al. Cospray-dried unfractionated heparin with L-leucine as a dry powder inhaler mucolytic for cystic fibrosis therapy. J Pharm Sci 2008;97:4857-4868. [PubMed: 18351636]

Staniforth, JN. Powder flow. In: Aulton, ME., editor. Pharmaceutics: The Science of Dosage Form Design. 2nd ed.. London: Churchill Livingstone; 2002. p. 205-208.

Strecker EP, et al. Inhalation bronchography using powdered calcium ioglycamic acid. Radiology 1979;130:303-309. [PubMed: 104359]

Szmigielski W, et al. Powdered diatrizoic acid for radiography of the respiratory tract. Part II. Clinical application. Acta Radiol 1991b;32:467-473.

Szmigielski W, et al. Powdered diatrizoic acid for radiography of the respiratory tract. Part I. Experimental investigation. Acta Radiol 1991a;32:415-420.

Tanomkiat W, Galassi W. Barium sulfate as contrast medium for evaluation of postoperative anastomotic leaks. Acta Radiol 2000;41:482-485. [PubMed: 11016771]

Telko MJ, Hickey AJ. Dry powder inhaler formulation. Respir Care 2005;50:1209-1227. [PubMed: 16122404]

Tsapis N, et al. Trojan particles: Large porous carriers of and *nanoparticles for drug delivery. PNAS 2002;99:12001-12005. [PubMed: 12200546]

Vanbever R, et al. Sustained release of insulin from insoluble inhaled particles. Drug Development Research 1999a;48:178-185.

Vanbever R, et al. Formulation and physical characterization of large porous particles for inhalation. Pharm Res 1999b;16:1735-1742. [PubMed: 10571280]

Walsham A, Larsen J. Adverse effects of barium sulfate in the biliary tract. Diagn Interv Radiol 2008;14:94-96. [PubMed: 18553283]

Wisner ER, et al. Iodinated nanoparticles for indirect computed tomography lymphography of the craniocervical and thoracic lymph nodes in normal dogs. Acad Radiol 1994;1:377-384. [PubMed: 9419515]

Yang ZY, et al. Production of ultrafine sumatriptan succinate particles for pulmonary delivery. Pharm Res 2008;25:2012-2018. [PubMed: 18581210] 
Young PM, et al. The influence of mechanical processing of dry powder inhaler carriers on drug aerosolization performance. J Pharm Sci 2007;96:1331-1341. [PubMed: 17455362]

Young PM, et al. Characterization of a surface modified dry powder inhalation carrier prepared by "particle smoothing". J Pharm Pharmacol 2002;54:1339-1344. [PubMed: 12396294] 


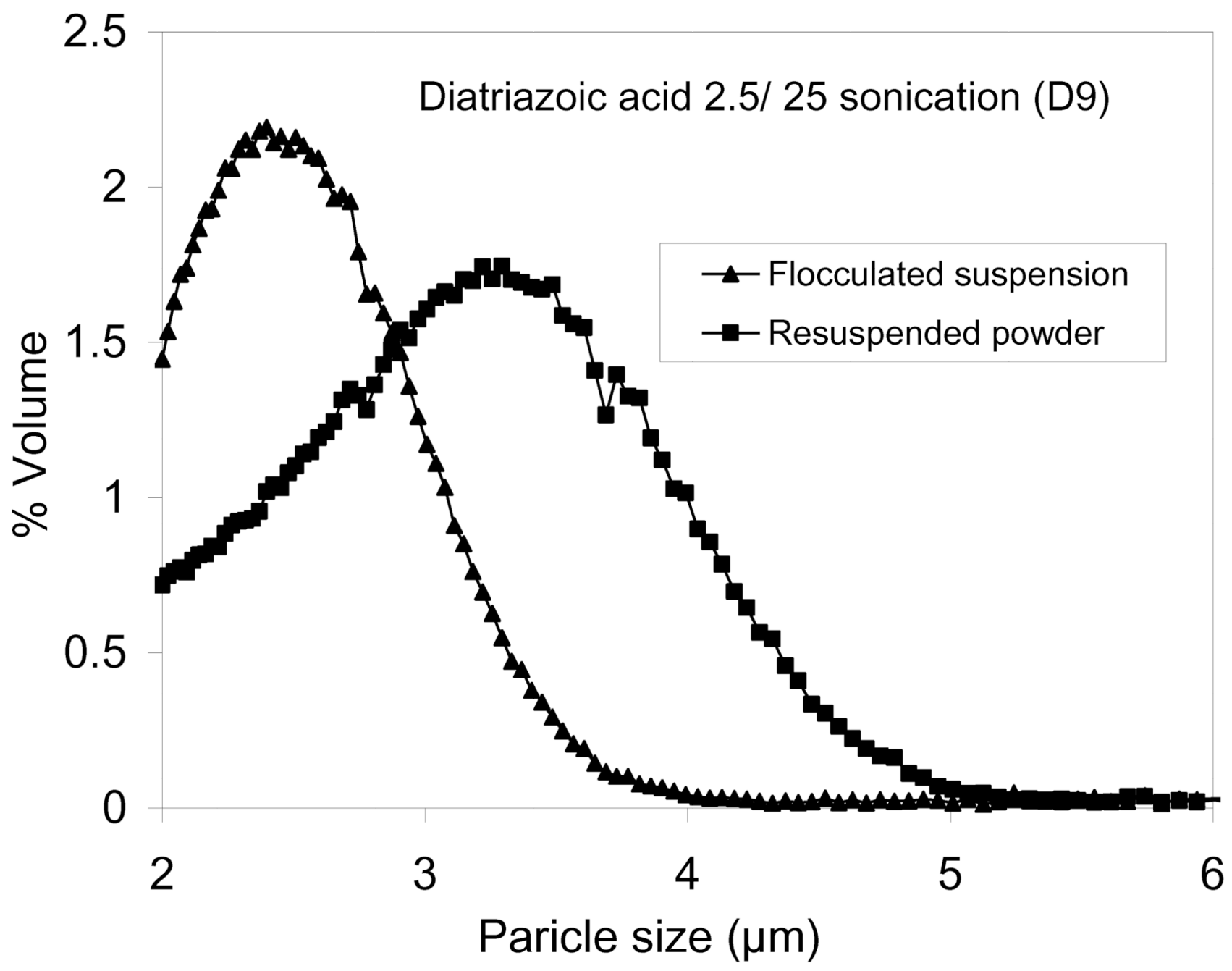

Figure 1.

The particle size distributions of diatrizoic acid nanoparticle agglomerates D9 after flocculation and resuspended after lyophilization. 


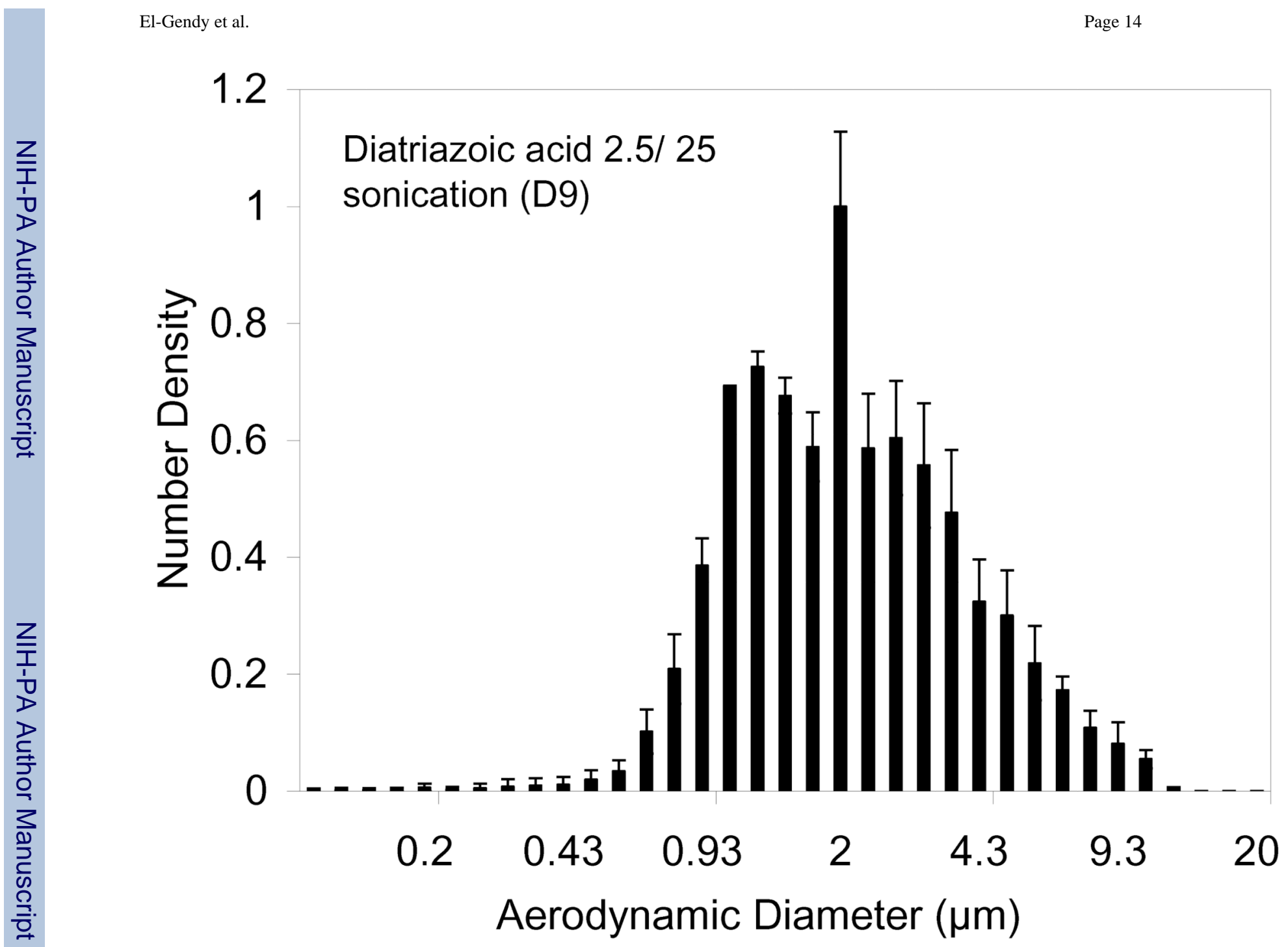

Figure 2.

Aerodynamic size distributions of diatrizoic acid nanoparticle agglomerates D9 after lyophilization. 


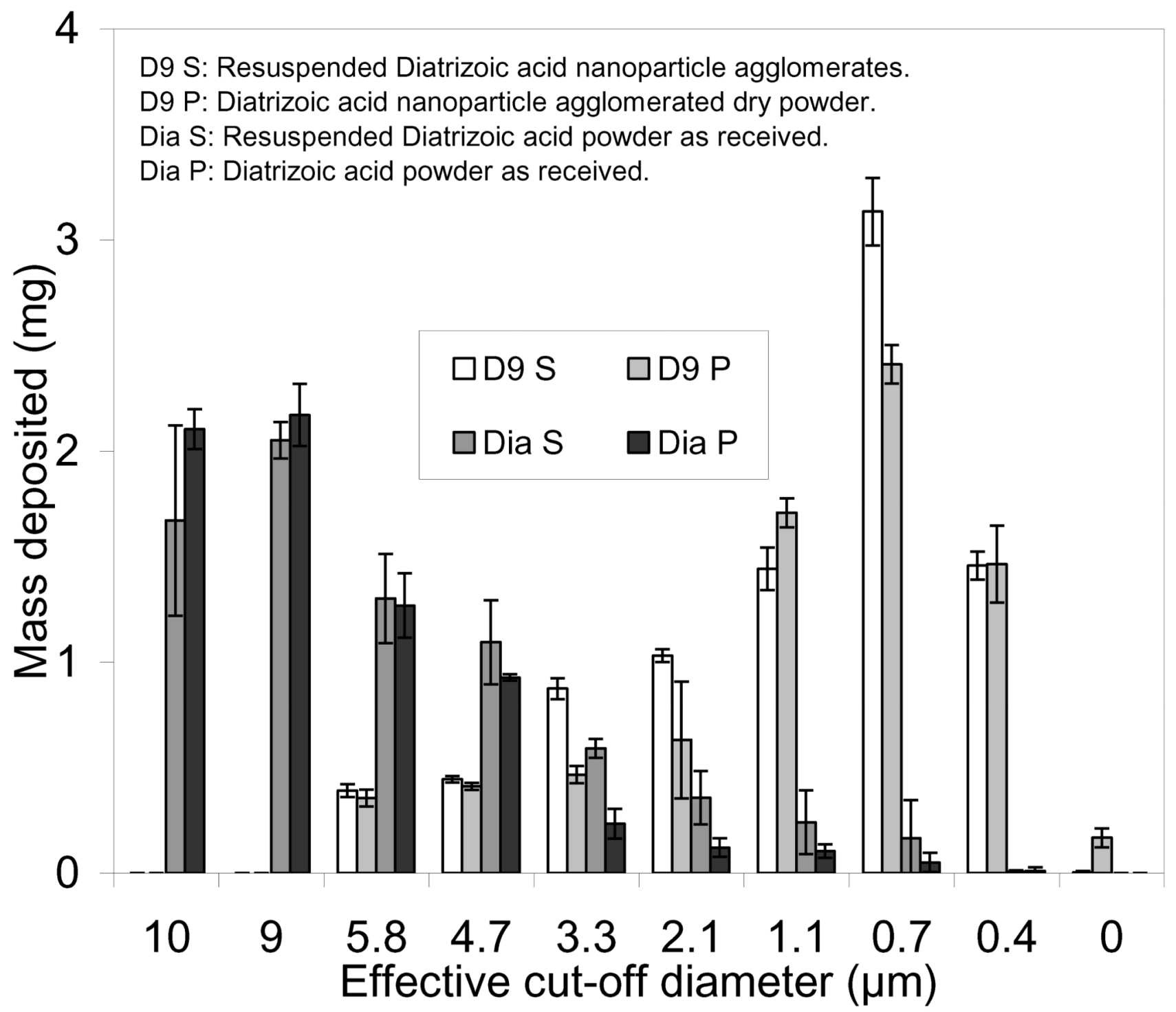

Figure 3.

The distribution of diatrizoic acid powder as received as well as nanoparticle agglomerate formulation (D9) deposited on the stages of a cascade impactor at a flow rate of $\sim 30 \mathrm{~L} / \mathrm{min}$. 

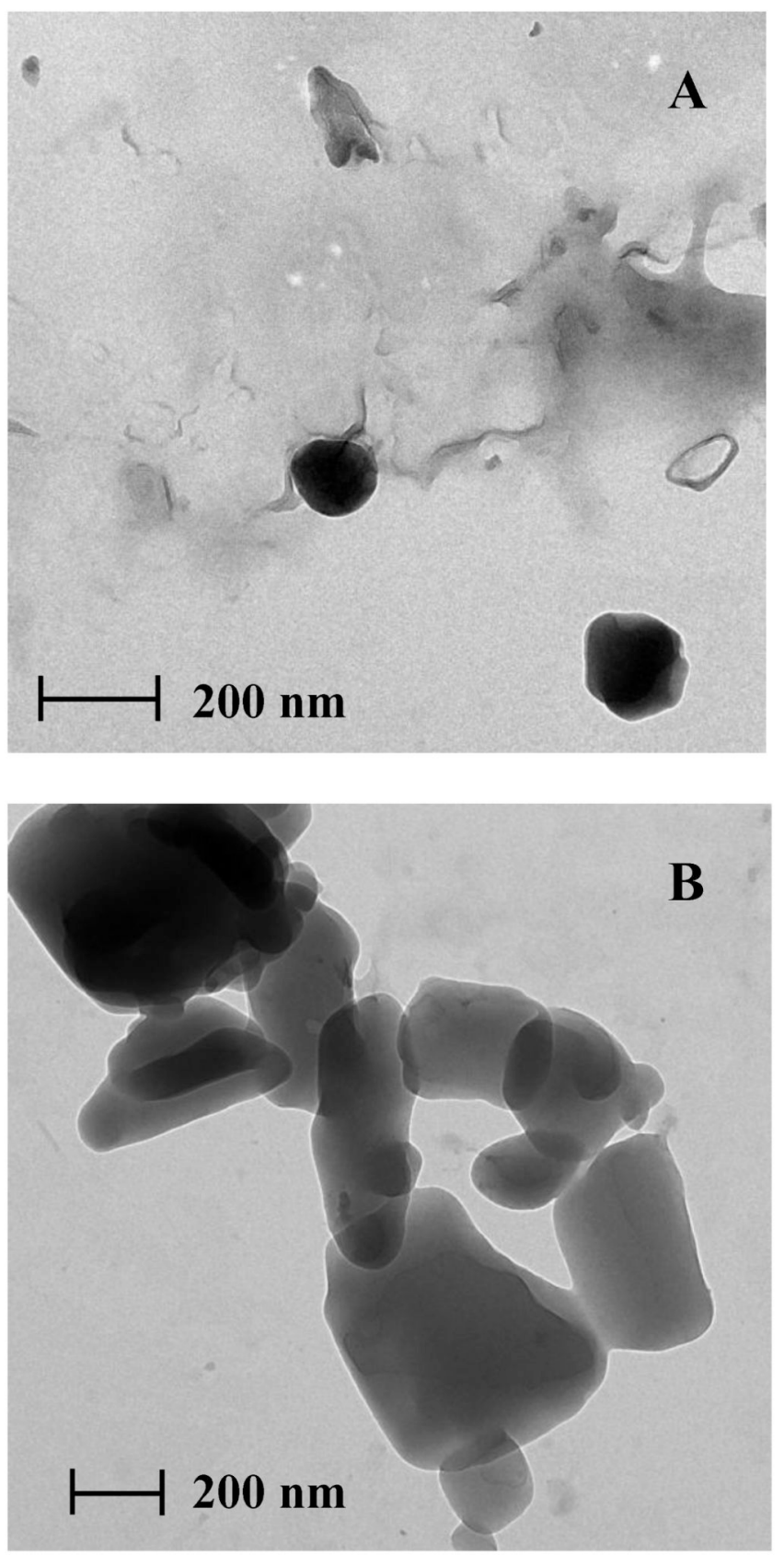

Figure 4.

Transmission electron micrographs of diatrizoic acid A) D9 nanoparticles and B) D9 nanoparticle agglomerates. 


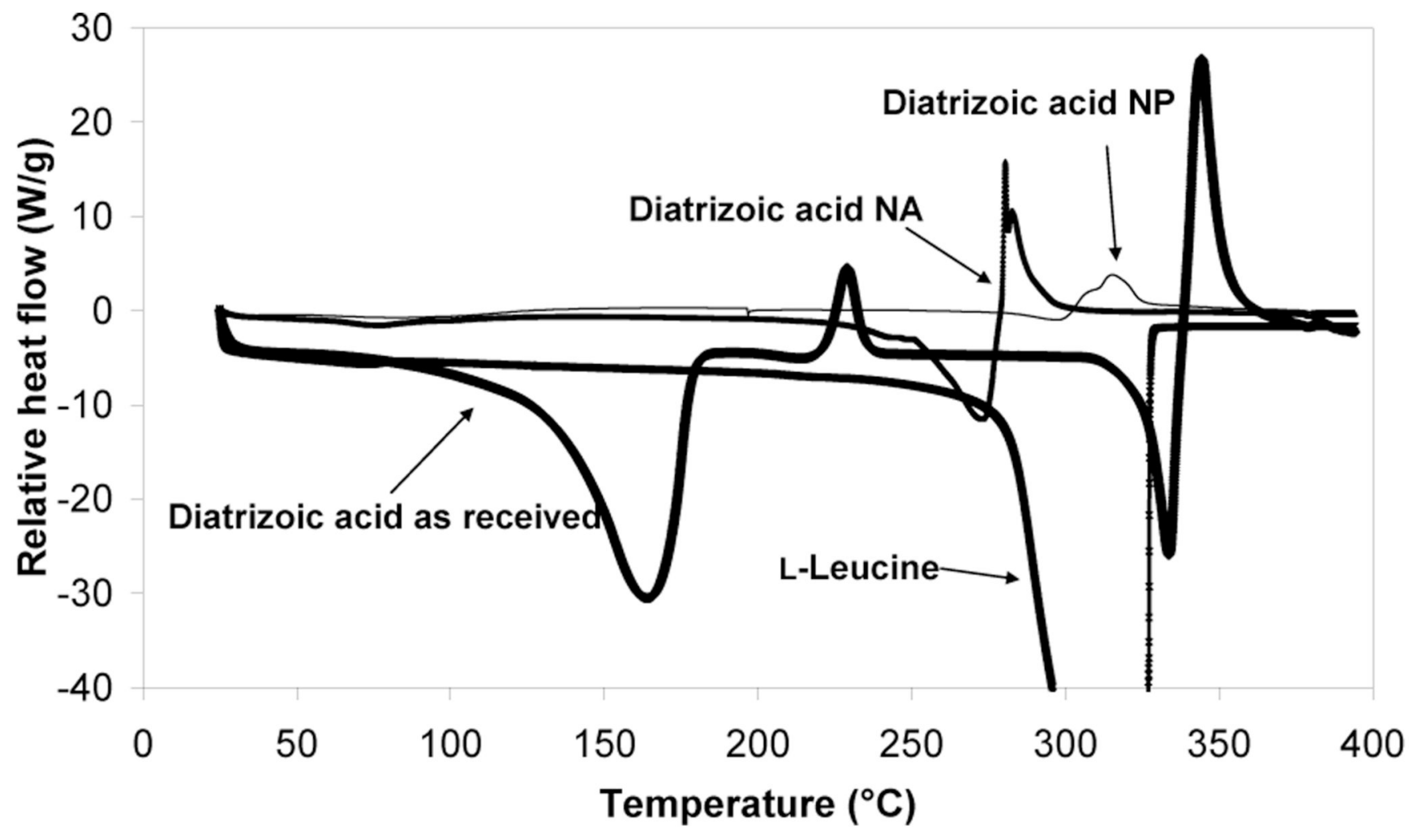

Figure 5.

Differential scanning calorimetry (DSC) thermograms for diatrizoic acid as received, nanoparticles (NP), nanoparticle agglomerates (NA) and $\mathrm{L}_{\mathrm{L}}$ leucine as received. 


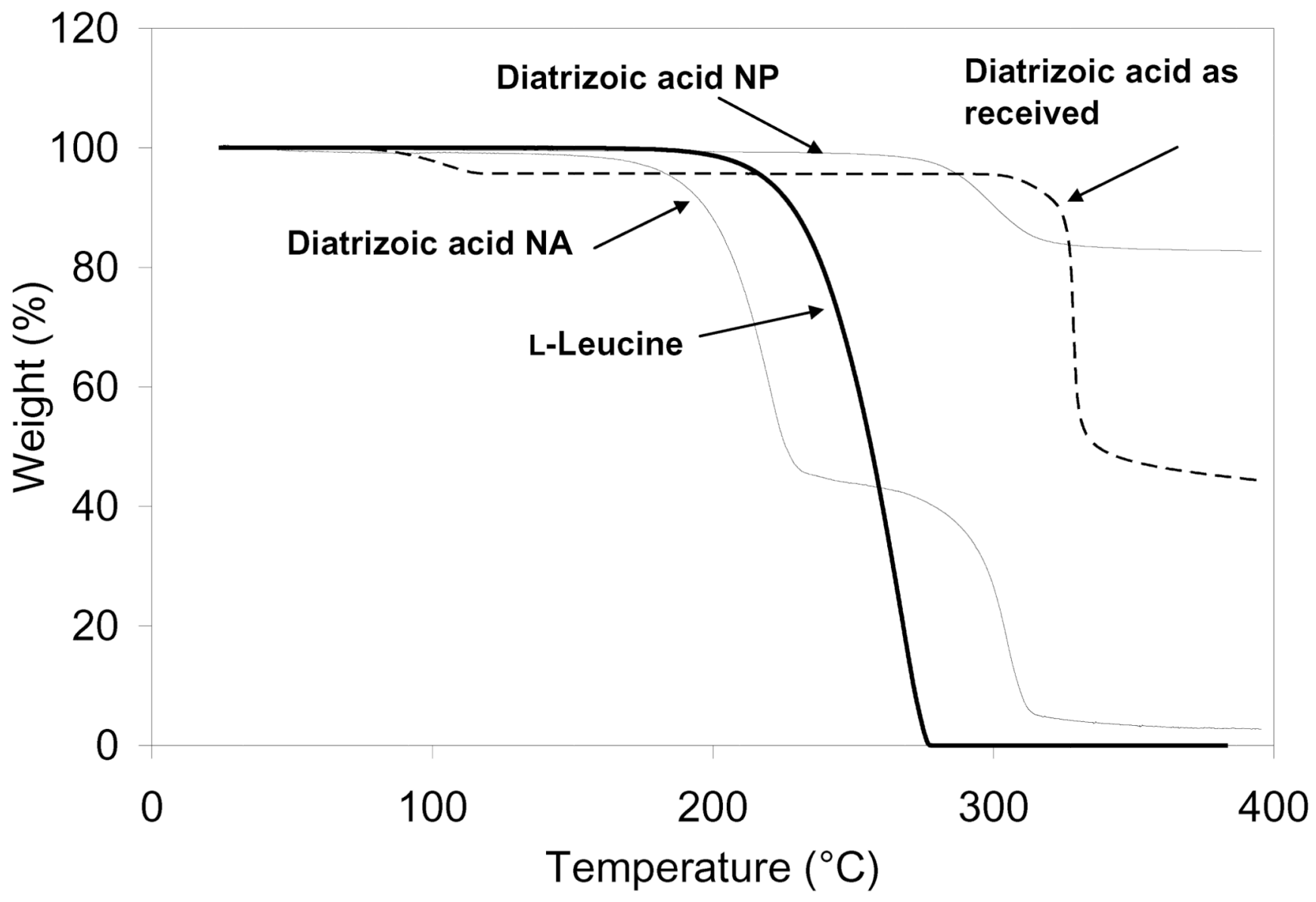

Figure 6.

Thermogravimetric analysis (TGA) for diatrizoic acid as received, nanoparticles (NP) and nanoparticle agglomerates (NA). 


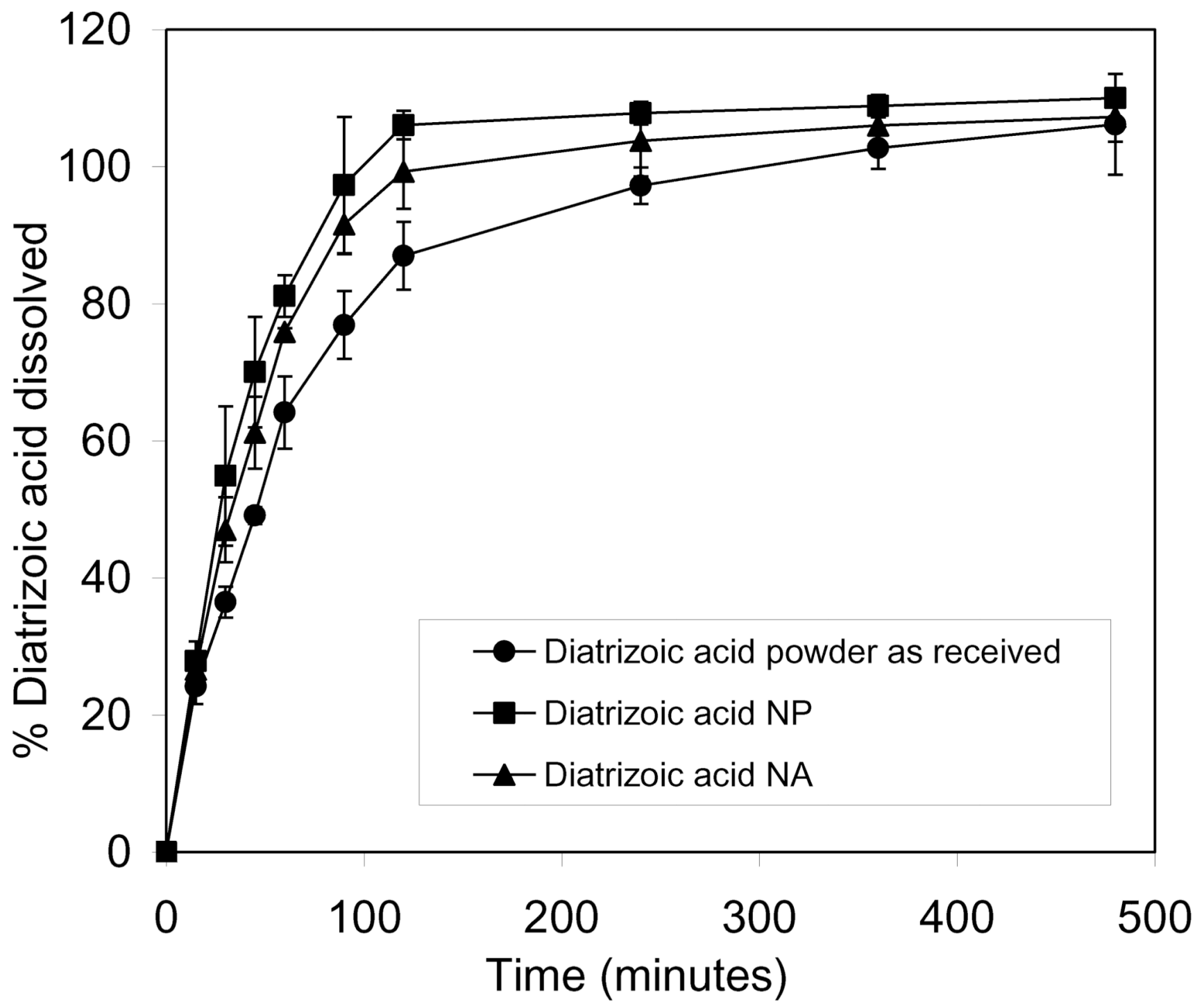

Figure 7.

Dissolution profiles of diatrizoic acid in PBS ( $\mathrm{pH}$ 7.4) from diatrizoic acid powder as received, the prepared D9 nanoparticle (NP) and nanoparticle agglomerate formulation (NA). 

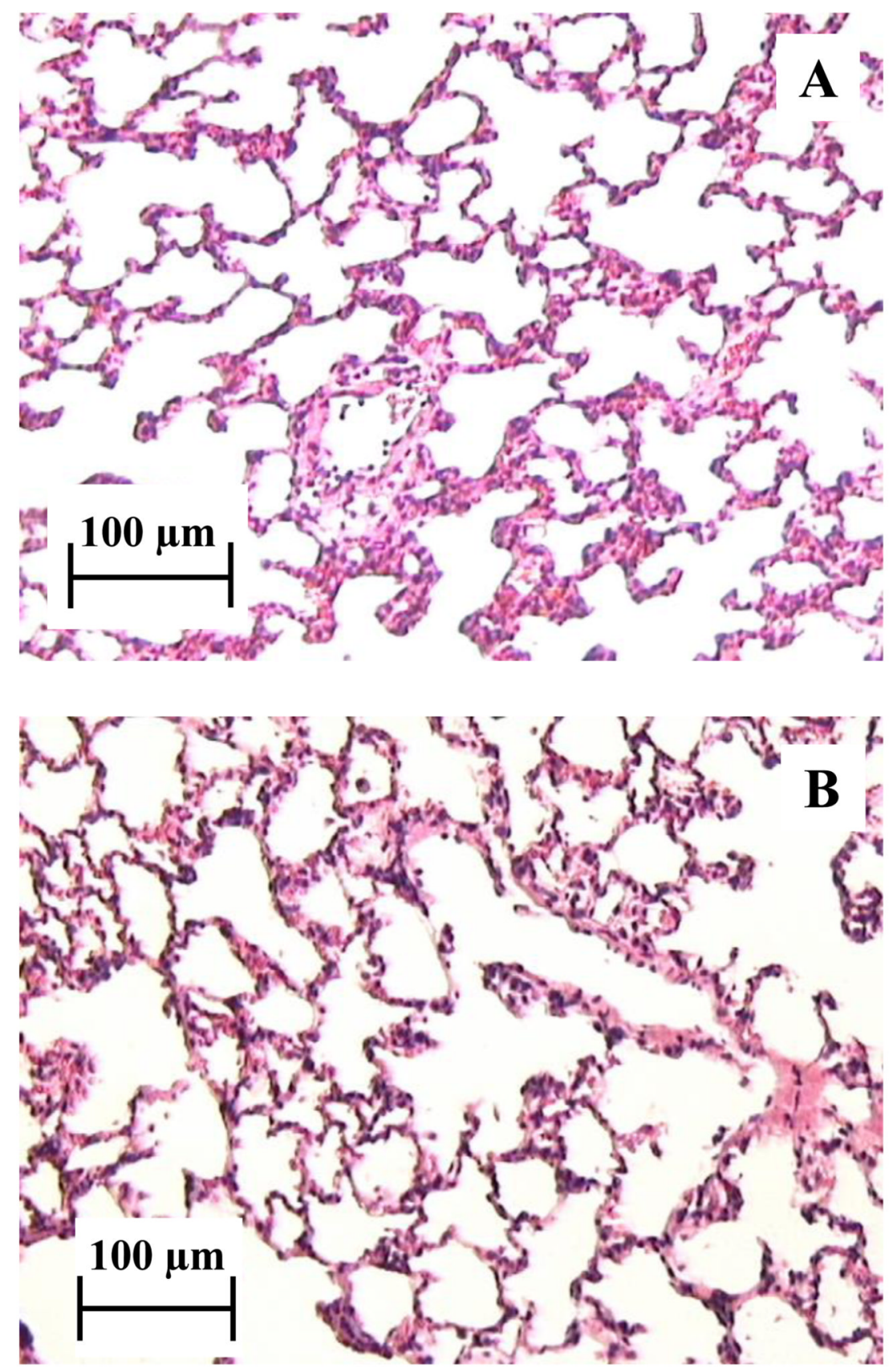

Figure 8.

Rat right lung histology images A) after $10 \mathrm{mg}$ insufflation of D9 nanoparticle agglomerates $(2 \mathrm{~h}$ post dose) and $\mathrm{B})$ normal lung tissue, no insufflation. 


\begin{tabular}{|c|c|c|c|c|c|c|c|c|c|c|}
\hline 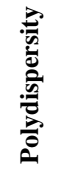 & \begin{tabular}{l}
\multicolumn{1}{c}{} \\
0 \\
+1 \\
$n$ \\
\end{tabular} & 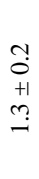 & $\begin{array}{l}-1 \\
0 \\
+1 \\
\text { ते } \\
0\end{array}$ & $\begin{array}{l}\overline{0} \\
\dot{0} \\
+1 \\
\text { +1 } \\
0\end{array}$ & 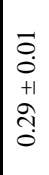 & 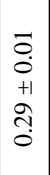 & $\begin{array}{l}-1 \\
0 \\
+1 \\
\tilde{0} \\
0\end{array}$ & $\begin{array}{l}\overrightarrow{0} \\
\dot{0} \\
+1 \\
\overrightarrow{0} \\
0\end{array}$ & 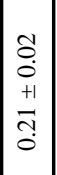 & $\begin{array}{l}\overrightarrow{0} \\
0 \\
0 \\
+1 \\
0 \\
0 \\
0 \\
0\end{array}$ \\
\hline 这 & $\begin{array}{l}J \\
= \\
+1 \\
\stackrel{+}{1}\end{array}$ & $\begin{array}{l}\hat{o} \\
\dot{0} \\
+1 \\
\dot{N}\end{array}$ & $\begin{array}{l}\text { m } \\
0 \\
+1 \\
\text { ¿ } \\
1\end{array}$ & $\begin{array}{l}n \\
0 \\
+1 \\
0 \\
\text { N }\end{array}$ & $\begin{array}{l}\hat{o} \\
0 \\
+1 \\
0 \\
0\end{array}$ & $\begin{array}{l}0 \\
0 \\
+1 \\
+1 \\
0 \\
i\end{array}$ & $\begin{array}{l}\tilde{r} \\
\vec{i} \\
+1 \\
\stackrel{d}{i}\end{array}$ & $\begin{array}{l}\stackrel{0}{\dot{m}} \\
+1 \\
\vec{N}\end{array}$ & 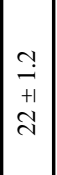 & 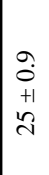 \\
\hline 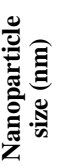 & $\begin{array}{l}\stackrel{+}{1} \\
+1 \\
\stackrel{N}{N}\end{array}$ & $\begin{array}{l}\hat{N} \\
+1 \\
D \\
\infty \\
\cdots\end{array}$ & $\begin{array}{l}n \\
0 \\
+1 \\
2 \\
\infty\end{array}$ & $\begin{array}{l}\vdots \\
\infty \\
+1 \\
\\
\infty\end{array}$ & $\begin{array}{l}= \\
+1 \\
\frac{0}{m}\end{array}$ & $\begin{array}{l}\infty \\
+1 \\
+1 \\
\stackrel{m}{m}\end{array}$ & $\begin{array}{l}n \\
n \\
+1 \\
v \\
q\end{array}$ & 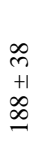 & 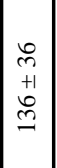 & \begin{tabular}{l}
$\tilde{6}$ \\
+1 \\
0 \\
\multirow{7}{\gamma}{}
\end{tabular} \\
\hline 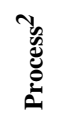 & is & \pm & in & $I$ & as & \pm & is & I & is & \pm \\
\hline 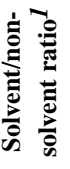 & $\frac{n}{i n}$ & $\frac{n}{i n}$ & $\frac{w}{n}$ & $\frac{n}{n}$ & $\stackrel{\infty}{\stackrel{\sim}{\sim}}$ & 文 & $\stackrel{\grave{~}}{\Xi}$ & 今ે & $\begin{array}{l}n \\
\tilde{n} \\
i \\
i\end{array}$ & 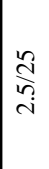 \\
\hline 吾 & $\bar{a}$ & $\tilde{n}$ & $\tilde{\theta}$ & $\overrightarrow{0}$ & $\ddot{s}$ & ๑̊ & $\hat{\theta}$ & $\stackrel{\infty}{\rho}$ & $\hat{A}$ & $\stackrel{\circ}{\circ}$ \\
\hline
\end{tabular}


Table 2

Characterization of diatrizoic acid nanoparticle agglomerates (NA) (values = average \pm S.D.).

\begin{tabular}{|c|c|}
\hline Characteristics & Formulation $\left(\mathbf{D 9}^{\boldsymbol{a}}\right)$ \\
\hline Geometric particle size $(\mu \mathrm{m})$ of NA before lyophilization & $2.4 \pm 1$ \\
\hline Geometric particle size $(\mu \mathrm{m})$ of lyophilized NA & $2.9 \pm 1$ \\
\hline Tap density $\left(\mathrm{g} / \mathrm{cm}^{3}\right)$ & $0.05 \pm 0.01$ \\
\hline $\mathrm{MMAD}_{\mathrm{A}}{ }^{b}$ of lyophilized NA & $2.1 \pm 2$ \\
\hline $\mathrm{MMAD}_{\mathrm{t}}{ }^{c}$ of lyophilized NA & $1.09 \pm 0.1$ \\
\hline Process yield of lyophilized NA (\%) & $86 \pm 3$ \\
\hline Loading Efficiency of lyophilized NA (\%) & $85 \pm 4$ \\
\hline
\end{tabular}

${ }^{a} \mathrm{D} 9=2.5 / 25$ ethanol/water using sonicator

${ }^{b}$ MMADA: Mass median aerodynamic diameter obtained from Aerosizer.

${ }^{c}$ MMADt: Theoretical mass mean aerodynamic diameter calculated from density measurements 

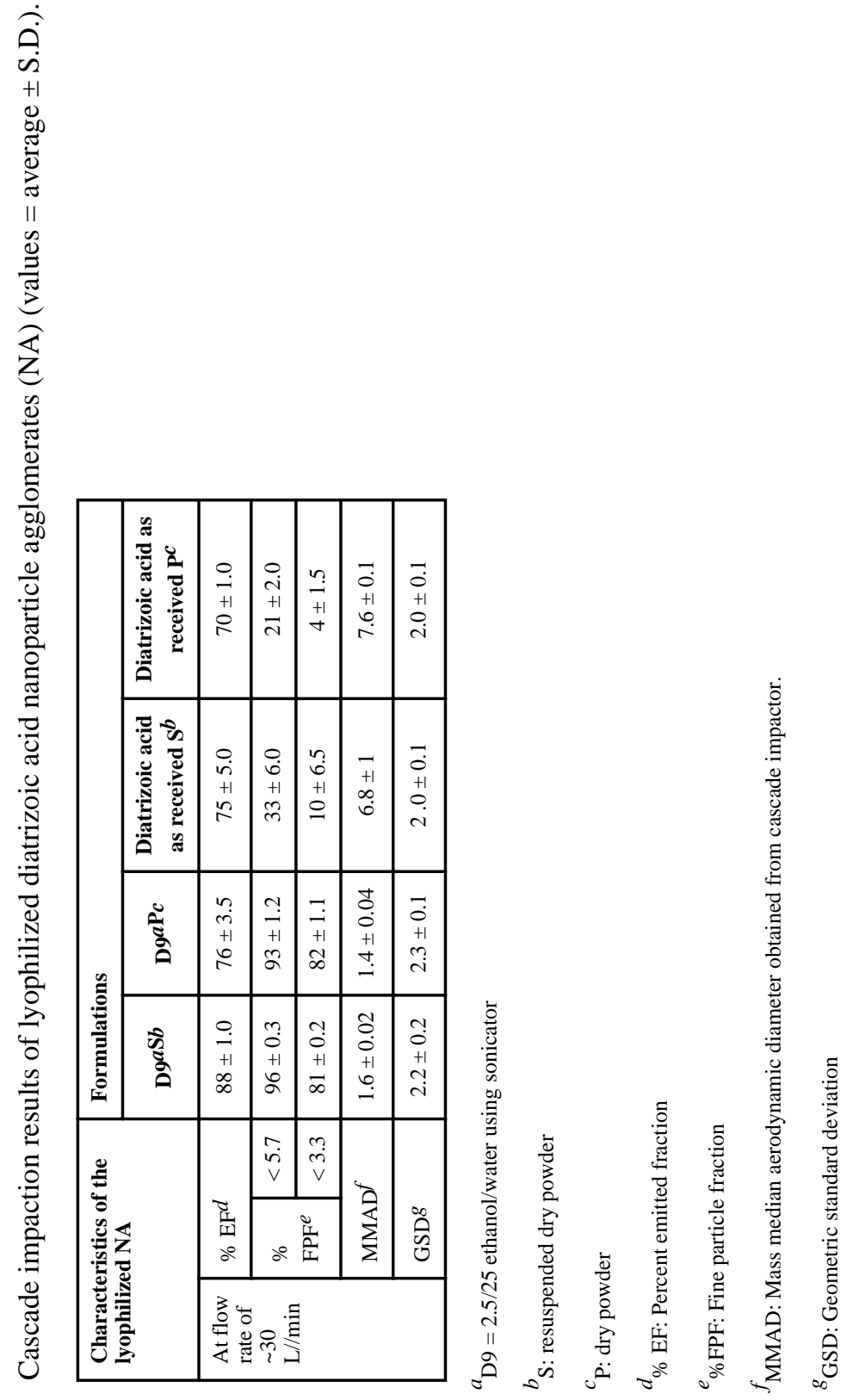

Int J Pharm. Author manuscript; available in PMC 2011 May 31. 
Table 4

Modeling of release of diatrizoic acid from the prepared nanoparticles and nanoparticle agglomerates.

\begin{tabular}{|l|l|l|l|l|}
\hline Formulations & Zero-order & First-order & Higuchi & $\begin{array}{l}\text { Order of } \\
\text { release }\end{array}$ \\
\hline $\begin{array}{l}\text { D9 } \\
\text { nanoparticles }\end{array}$ & 0.63 & 0.603 & 0.902 & Higuchi \\
\hline $\begin{array}{l}\text { D9 nanoparticle } \\
\text { agglomerates }\end{array}$ & 0.71 & 0.61 & 0.91 & Higuchi \\
\hline $\begin{array}{l}\text { Diatrizoic acid } \\
\text { as received }\end{array}$ & 0.786 & 0.69 & 0.92 & Higuchi \\
\hline
\end{tabular}

${ }^{a}$ D9 $=2.5 / 25$ ethanol/water using sonicator 